\title{
Seroprevalence of Hepatitis B, Hepatitis C and Syphilis in Antenatal Women in Rajkot, Gujarat, India
}

\author{
V. Gosalia Ekta ${ }^{1}$, Megha Gevariya ${ }^{1 *}$ and B. Vasa Punit ${ }^{2}$ \\ ${ }^{1}$ Department of Microbiology, P.D.U. Medical College, Rajkot, India \\ ${ }^{2}$ Department of Obstetrician and Gynecolgy, Swaminarayan Hospital, Sardhar, Rajkot, India \\ *Corresponding author
}

\section{A B S T R A C T}

\section{Keywords \\ Antenatal women, Hepatitis B, \\ Hepatitis C, New \\ born, \\ Seroprevalance, \\ Syphilis}

\section{Article Info}

Accepted:

04 August 2019

Available Online:

10 September 2019
The epidemiology of viral hepatitis and syphilis in antenatal patient is of paramount importance for health planner and program managers. This study was conducted to assess to know the seroprevalnce of Hepatitis B Hepatitis C and syphilis in antenatal patient and to re-evaluate the need for routine antenatal care screening. All samples were tested to detect HbsAg by enzyme linked immunosorbent assay (ELISA), anti HCV antibody by ELISA and antibodies to Treponema palladium by qualitative Rapid Plasma Regain (RPR). Total 1000 samples were tested. Out of which seropositivity of hepatitis B virus (HBV) was $1.9 \%$, hepatitis $\mathrm{C}$ virus (HCV) was $0.2 \%$ and syphilis was $0.4 \%$. Out of 1000 samples no coinfection was found between hepatitis $\mathrm{B}$ hepatitis $\mathrm{C}$ and syphilis. This study can helpful to health care professionals to treat antenatal patient more efficiently. Early diagnosis of infection in antenatal period is helpful for prevention of transmission, Proper management and early initiation of treatment to new born.

\section{Introduction}

Viral hepatitis during pregnancy is associated with a high risk of maternal complications, has a high rate of vertical transmission causing foetal and neonatal hepatitis and has been reported as a leading cause of maternal mortality ${ }^{(1,2)}$. Ten percent of infants born to women with acute HBV infection during the first trimester of pregnancy are $\mathrm{HbsAg}$ positive at birth and 80 to $90 \%$ of neonates become HbsAg positive without prophylactic therapy, if acute maternal infection develops during the third trimester of pregnancy (3) According to Okada et al., ${ }^{(4)} 85 \%$ of neonatal HBV infections are caused due to intrapartum exposure to infectious blood and vaginal secretion and the remaining $15 \%$ are caused by haematogenous transplacental viral spread.

In antenatal women, vertical transmission of $\mathrm{HCV}$ occurs in $3-10 \%$. WHO calculates that unsafe healthcare devices account for 2.3 million new $\mathrm{HCV}$ infections per year and 2,00,000 HCV-related premature deaths 
mostly in developing countries $^{(5)}$. Transmission of $T$. pallidum from a syphilitic woman to her foetus through the placenta may occur at any stage of pregnancy, but the lesions of congenital syphilis generally have their onset after the fourth month of gestation when foetal immunologic competence begins to develop. The risk of infection of the foetus during untreated early maternal syphilis is estimated to be 75 to $95 \%$, decreasing to approximately $35 \%$ for maternal syphilis of two years duration. ${ }^{(6)}$

\section{Materials and Methods}

This study was conducted to determine the prevalence of Hepatitis B Virus Surface Antigen (HbsAg), antibodies to hepatitis C virus, antibodies to Treponema pallidum among patients attending the antenatal clinic at Swaminarayan hospital, Sardhar, Rajkot Gujarat. Serum samples from 1000 cases were collected from December 2016 to December 2017. These samples were tested for Hepatitis B Surface Antigen (HbsAg) and antibody to hepatitis $\mathrm{C}$ by ELISA (enzyme-linked immunosorbent assay). The RPR syphilis screening test, which is a macroscopic nontreponemal flocculation card test for the detection and quantitation of anti-lipoidal antibodies in serum or plasma.

Five millilitre blood samples were collected using a sterile plain vacutainer and serum was separated by centrifugation into sterile vials. Needles were destroyed using a needle destroyer and discarded in $1 \%$ hypochlorite solution.

\section{Laboratory Tests for HbsAg}

The serum samples were tested for Hepatitis B Surface Antigen (HbsAg) using microscreenHbsAg ELISA, which is a direct non-competitive solid phase enzyme immunoassay in serum or plasma.

\section{Laboratory tests for HCV antibodies}

The serum samples were tested for $\mathrm{IgG}$ antibodies to HCV using Qualisa HCV test kit, a third generation ELISA in serum or plasma. Microwells were coated with $\mathrm{HCV}$-specific recombinant antigen from the $\mathrm{C}$-core (structural), E1 and E2 (envelop proteins), NS3, NS4 and NS5 (nonstructural) regions of the HCV genome.

\section{Laboratory tests for syphilis}

The serum samples were tested for the presence of treponemal antibodies using carbogen. The RPR screening test is a macroscopic nontreponema flocculation card test for the detection of anti-lipoidal antibodies present in serum or plasma.

\section{Results and Discussion}

A total of 1000 samples were tested from antenatal patients for hepatitis B virus, hepatitis $\mathrm{C}$ virus, and syphilis.

HBsAg positive patients were 19 out of 1000 samples; so the prevalence for HbsAg was $1.9 \%$ as shown in Table 1.

Among the antenatal cases, prevalence of HbsAg was maximum in the 24-29 years of age group (52.63\%) and the prevalence in the second trimester was the highest $(42.16 \%)$, followed by the third $(31.57 . \%)$ and first trimester $(26.31 \%)$ as shown in Table 2.

Anti HCV antibody was found in 2 patients, thus the overall prevalence for anti-HCV was $0.2 \%$ as shown in Table 1 . Seroprevalence was same in age group 24-30 years (50\%) and 31-37 years (50\%) shown in Table 2. One sample was positive for $\mathrm{HCV}$ in first trimester $(50 \%)$ and one sample was positive in second trimester $(50 \%)$. Out of 1000 samples 4 samples are positive for anti-treponema 
antibody test, so overall prevalence was $0.4 \%$ shown in Table 1, of one patient was positive in second trimester(25\%) and three patients were positive in $3^{\text {rd }}$ trimester $(75 \%)$.

Table.1 Hepatitis B, hepatitis C and syphilis among antenatal cases in various age groups

\begin{tabular}{|c|c|c|c|c|c|c|}
\hline \multirow{2}{*}{$\begin{array}{c}\text { Type Of } \\
\text { Infections }\end{array}$} & \multirow[t]{2}{*}{ Results } & \multicolumn{4}{|c|}{ Age groups(years) } & \multirow[t]{2}{*}{ Total } \\
\hline & & $17-23$ & $24-30$ & $31-37$ & $>37$ & \\
\hline \multirow[t]{3}{*}{ HBsAg } & Positive & 3 & 10 & 6 & 0 & 19 \\
\hline & Negative & 230 & 519 & 194 & 38 & 981 \\
\hline & Total & 233 & 529 & 200 & 38 & 1000 \\
\hline \multirow[t]{3}{*}{ HCV } & Positive & 0 & 1 & 1 & 0 & 2 \\
\hline & Negative & 233 & 528 & 199 & 38 & 998 \\
\hline & Total & 233 & 529 & 200 & 38 & 1000 \\
\hline \multirow[t]{3}{*}{ Syphilis } & Positive & 0 & 3 & 1 & 0 & 4 \\
\hline & Negative & 233 & 526 & 199 & 38 & 996 \\
\hline & Total & 233 & 529 & 200 & 38 & 1000 \\
\hline
\end{tabular}

Table.2 Hepatitis B, hepatitis C and syphilis among antenatal cases in various trimesters

\begin{tabular}{|c|c|c|c|c|c|}
\hline \multirow{2}{*}{$\begin{array}{c}\text { Type Of } \\
\text { Infections }\end{array}$} & \multirow[t]{2}{*}{ Results } & \multicolumn{3}{|c|}{ Trimester } & \multirow[t]{2}{*}{ Total } \\
\hline & & $1^{\mathrm{st}}$ & $2^{\mathrm{nc}}$ & $3^{\text {rd }}$ & \\
\hline \multirow[t]{3}{*}{ HBsAg } & Positive & 5 & 8 & 6 & 19 \\
\hline & Negative & 325 & 481 & 175 & 981 \\
\hline & Total & 330 & 489 & 181 & 1000 \\
\hline \multirow[t]{3}{*}{$\mathrm{HCV}$} & Positive & 1 & 1 & 0 & 2 \\
\hline & Negative & 329 & 488 & 181 & 998 \\
\hline & Total & 330 & 489 & 181 & 1000 \\
\hline \multirow[t]{3}{*}{ Syphilis } & Positive & 0 & 1 & 3 & 4 \\
\hline & Negative & 330 & 488 & 178 & 996 \\
\hline & Total & 330 & 489 & 181 & 1000 \\
\hline
\end{tabular}

In our study, HbsAg prevalence rate was $1.9 \%$ among antenatal women, which is comparable with study like Biswas et al., $(2.3 \%)^{(7)}$, Gupta et al., $(2.5 \%)^{(8),}$ Panda et al., $(2.6 \%)^{(9)}$. Results of our study were reported higher in comparison to Seyed Reza et al., ${ }^{(10)}$ $(0.6 \%)$. Results of our study were lower than the rates reported by Dinakaran et al., $(3.8 \%)^{(11)}$, Fisseha Walle et al., $(5.3 \%)^{(12)}$ and Aba et al., $(3.9 \%)^{(13)}$, Mittal et al., $(6.3 \%)^{(14)}$, Gill et al., $(5 \%)^{(15)}$, Nayak et al., $(3.7 \%)^{(16)}$.

Due to strong possibility of vertical transmission, diagnosis of acute or chronic
HBV infection in pregnant women and justifies mandatory antepartum serum $\mathrm{HBsAg}$ screening. ${ }^{(17)}$ Screening of HBsAg will reveal previously unsuspected chronic HBV infection in young, otherwise healthy, individuals. Antepartum screening has the added benefit of making it possible to refer such patients for appropriate antiviral therapy which is helpful to prevent significant liver damage and associated complication.

India falls into the intermediate endemicity area in the prevalence of HBV infection, which is $3-4 \%{ }^{(17)}$. vertical and horizontal 
transmission in the perinatal period and early childhood are the major ways of propagation of this infection in India.

Large scale studies on the estimates of the prevalence of $\mathrm{HCV}$ infection and risk behaviour of $\mathrm{HCV}$ infection in the Indian population are yet to be undertaken. Of the 1000 samples, only two samples were positive for anti-HCV antibodies $(0.2 \%)$, which are low compared to the rates reported by Ashok Kumar et al., (1.03\%) ${ }^{(18)}$ and Harshita et al., $(1.2 \%)^{(19)}$ but similar to the rates reported by Nagababu et al., $(0.21 \%){ }^{(20)}$ and Seyed Reza et al., $(0.2 \%)^{(10)}$

In India, the prevalence of $\mathrm{HCV}$ is $1-2 \%$. According to the National Centre for Disease Control (NCDC). HCV is a bloodborne pathogen; about $75-85 \%$ patients with $\mathrm{HCV}$ will develop chronic infection and about 10$15 \%$ develops liver cirrhosis. Mother to child transmission rate of $\mathrm{HCV}$ has been estimated around 5\%. Complications of $\mathrm{HCV}$ during pregnancy associated with premature contractions, placental separation, preterm delivery, vaginal bleeding, gestational diabetes mellitus and mortality. 13-15, among pregnant women, hepatic dysfunction is a common problem caused by viral hepatitis. So, targeted screening is not sufficient and universal screening would cause cost constraints especially in resource-poor countries.

The prevalence rate of syphilis in our study $(0.4 \%)$ was compared to study reported by Nidhi Nair et al., $(0.36 \%)^{(21)}$. The prevalence rate of our study was higher in comparison to rate reported by ShaziaParveen et al., $(0.0 \%)^{(22)}$ and lower than that, Harshita et al., $(1.05 \%)^{(18)}$ and Gupta et al., $(1.47 \%)^{(23)}$,by Kebede et al., (2.9\%) ${ }^{(24)}$, In India, available information indicates that the prevalence of maternal syphilis has remained at around $1.5 \%$ between 2003 and 2007 (strategy of
WHO, 2009). Pregnant women with syphilis can transmit the infection to their foetus causing congenital syphilis. In addition, maternal syphilis can also lead to other serious adverse outcomes of pregnancy such as stillbirth or spontaneous abortion, low birth weight babies or serious infections that are associated with an increased risk of perinatal death.

Conclusion of the study is as follows:

So, increasing awareness of transmission and regular screening for $\mathrm{HbsAg}, \mathrm{HCV}$, and syphilis among antenatal patient is strongly recommended. The findings of this study support the opinion that all antenatal women should be screened for infection at the first antenatal clinic visit, so that adequate clinical management can be planned for them. Early diagnosis of infection in antenatal period is helpful for proper management and initiation of treatment to prevent vertical transmission. This study can help the health professionals to efficiently treat antenatal patients and new born.

\section{References}

1. Ornoy A, Tenenbaum A. Pregnancy outcome following infections by Coxsackie, echo, measles, mumps, hepatitis, polio and encephalitis viruses. Reprod Toxicol 2006; 21(4): 446-457.

2. Edmunds WJ, Medley GF, Nokes DJ. The transmission dynamics and control of hepatitis Bvirus in The Gambia. Stat Med 1996; 30(15): 2215-2233.

3. Sweet RL. Hepatitis B infection in pregnancy. Obstet Gynecol Report 1990; 2: 128 .

4. Okada K, Kamiyama I, Inomata M, et al., $E$ antigen and anti-E in the serum of asymptomatic carrier mothers as indicators of positive and negative transmission of hepatitis B virus to their 
infants. N Engl J Med 1976; 294(14): 746-749.

5.Irshad M, Acharya SK, Joshi YK (1995) Prevalence of hepatitis C virus antibodies in the general population and in the selected groups of patients in Delhi. Indian J Med Res 102: 162-164.

6. Kasper L, Braunwald E, Fauci A, et al., Harrison's principles of internal medicine. 16th edn. New York: McGraw-Hill 2005: p. 2607.

7. Biswas SC, Gupta I, Ganguly NK, Chawla Y, Dilawari JB (1989) Prevalence of hepatitis B surface antigen in pregnant mothers and its perinatal transmission. Trans R Soc Trop Med Hyg 83: 698700.

8.Gupta I, Sehgal A, Sehgal R, Ganguly NK (1992) Vertical transmission of hepatitis $B$ in North India. J Hyg Epid MicrobiolImmunol 36: 263-267.

9. Panda, S.K., Ramesh, R., Rao, K.V.S., Gupta, A., Zuckerman, A.J., Nayak, N.C. 1991. Comparative evaluation of the immunogenicity of yeast derived (recombinant) and plasma derived Hepatitis B vaccine in infants. J. Med. Virol., 35: 297302.

10. Mohebbi SR, Sanati A, Cheraghipour K, et al., Hepatitis $\mathrm{C}$ and hepatitis B virus infection: epidemiology and risk factors in a large cohort of pregnant women in Lorestan, west of Iran. Hepatitis 2011; 11(9): 736-739.

11. Sharavanan TKV, Premalatha E, Dinakaran N, et al., Seroprevalence of hepatitis B surface antigen among rural pregnant women attending a tertiary care hospital. Scholars Journal of Applied Medical Sciences 2014; 2(4C): 1351-1354.

12. Walle, F Asrat D, Alem A, et al., Prevalence of hepatitis B surface antigen among pregnant women attending antenatal care service at Debre Tabor Hospital, Northwest
Ethiopia. Ethiopia J Health Science 2008; 17(1): 14-16.

13. Aba HO, Aminu M. Seroprevalence of hepatitis B virus serological markers among pregnant Nigerian women. Annals of African Medicine 2016; 15(1):20-27.

14. Mittal SK, Rao S, Rastogi A, Aggarwal V, Kumari S (1996) Hepatitis B, potential of perinatal transmission in India. Trop Gastroenterol 17: 190-192.

15. Gill HH, Majumdar PD, Dhunjibhoy KR, Desai HG (1995) Prevalence of hepatitis $\mathrm{B}$ e antigen in pregnant women and patients with liver disease. $\mathrm{J}$ Assoc Physicians India 43: 247-248.

16. Nayak NC, Panda SK, Zuckerman AJ, Bhan MK, Guha DK (1987) Dynamics and impact of perinatal transmission of hepatitis B virus in North India. J Med Virol., 21: 137-145.

17. ACOG Technical bulletin (1992) Hepatitis in pregnancy. No. 174 November Hepatitis in pregnancy. ACOG Technical Bulletin Number 174-November 1992 (1993) Int J Gynaecol Obstet., 42: 189-98

18. Kumar A, Sharma KA, Gupta RK, et al., Prevalence \& risk factors for hepatitis C virus among pregnant women. Indian $\mathrm{J}$ Med Res 2007; 126(3): 211-215.

19. Harshita, Malhotra S, Devi $\mathrm{P}$, et al., Seroprevalence of HIV, HBsAg, HCV \& Syphilis in pregnant women: readdressing the need for antenatal screening. IJSR 2015; 4(9): 303-304.

20. Pyadala N, Maity S, Kothapalli J, et al., Seroprevalence of HCV infection among pregnant women in a rural teaching hospital, Sangareddy. International Journal of Research and Development in Pharmacy and Life Sciences 2016; 5(4): 2251-2254.

21. Nair N, Urhekar AD, Pachpute S, et al., Incidence of syphilis among pregnant women attending a tertiary care 
hospital. Int J Cur Microbial App Sci 2013; 2(8): 79-84.

22. Parveen SS, Madhavi S. Antenatal screening for HIV, hepatitis B and syphilis in a tertiary care hospital. Int J Cur Microbial App Sci 2015; 4(12): 318-322.

23. Gupta N, Gautam V, Sehgal R, et al., Screening by VDRL test to detect hidden cases of syphilis. Indian Journal of Medical Microbiology 2003; 21(2): 118-120.

24. Kebede, E., Chamiso, B. 2000. Prevalence of syphilis in pregnancy in Addis Ababa. East Afr. Med. J., 77: 212-216.

\section{How to cite this article:}

Gosalia Ekta, V., Megha Gevariya and Vasa Punit, B. 2019. Seroprevalence of Hepatitis B, Hepatitis C and Syphilis in Antenatal Women in Rajkot, Gujarat. Int.J.Curr.Microbiol.App.Sci. 8(09): 643-648. doi: https://doi.org/10.20546/ijcmas.2019.809.077 